\title{
Studies on the Effect of Different Solar Dryers on the Vitamin Content of Tomato (Solanum lycopersicon)
}

\section{J. I. Eze*}

National centre for energy research and development, University of Nigeria, Nsukka, Enugu state, Nigeria

\begin{abstract}
Samples of tomato fruits were dried under four different conditions: open-air sun drying method and by using three different models of integral passive solar dryers which include Green house solar dryer, Sun-tracking solar dryer and Latitudinal box solar dryer. The fresh tomato samples and the dried samples were analysed for vitamins A, C and $\mathrm{E}$. The results showed a significant difference in the concentrations of Vitamins A, C and E between the fresh and the dried samples for all drying systems. While Vitamins $C$ reduced in concentration for all dried samples, Vitamins $A$ and $E$ increased significantly with open-air system having the highest value in vitamin $C$ concentration while latitudinal box dryer gave the best result in terms of vitamins $A$ and $E$ retention. All year round availability of tomato could be enhanced by chipping and drying. Packaging and marketing of dried chips in small quantities could be a lucrative entrepreneurial endeavour for the business minded.
\end{abstract}

Keywords: Concentration; Open-air; Passive; Ripe; Sun

Nomenclature: CRD: Completely Randomized Design; D.F: Degree of Freedom; F-LSD: Fisher's Least Significant Difference; $\mathrm{H}_{\mathrm{o}}$ : Null Hypothesis; r: Replications; $t_{a}$ : Treatment Sources; UVs: Ultra Violet Rays; s: Standard Deviations; t: Test Value; $x$ : Individual Vitamin Value

\section{Introduction}

Tomato is the fruit of the plant- Solanum lycopersicon from the family of solanacea (night shade). It is an annual crop which can grow to a height of $70-200 \mathrm{~cm}$. Tomato now grown worldwide for its edible fruits, is native to the western side of South America. There are about 7500 tomato varieties with the most widely grown commercial tomatoes in the range of 5-6 cm diameter. Most cultivars produce red fruit, but a number of cultivars with yellow, orange, pink, purple, green, black, or white fruit are also available. The tomato fruit is consumed in diverse ways, including raw, as an ingredient in many dishes and sauces, and in drinks. Tomato fruits are high in beta carotenes, vitamins A and C [1]. Simple observation shows that like every other fruits, preservation of tomato is at a very low level in Nigeria [2]. Storing the fruit fresh by refrigeration or drying mechanically can hardly be attained due to epileptic power supply in the country [3]. In this respect, solar drying could be a good option.

Sun drying is a cheap method of preserving fruits and vegetables because it uses sunlight as its source of heat. However, it is generally accepted that open-air sun drying has limitations due to dust contamination, bird and rodent attacks, fungal attacks and the risk associated with sudden rainfall upon the product being dried [3]. Several works have been reported on the development and evaluation of solar dryers to mitigate the limitations of open-air sun drying [3-5]. Solar drying combines the advantages of traditional open-air drying and industrial methods. This according to [6] requires low investment costs but yields high product quality. The use of solar drying systems by farmers is still unpopular in Nigeria. Most of these dryers are very simple and easy to construct using local materials. Most of the dryers were designed and evaluated only in comparison with open-air drying method [6-10]. Comparative evaluation is seldom reported. In this paper, three different models of the passive solar dryers were selected for comparison using tomato as a test sample to determine the effect of these dryers on its nutrient content namely vitamins $\mathrm{A}, \mathrm{C}$ and $\mathrm{E}$.

\section{Materials and Methods}

\section{Drying method}

Three models of passive solar dryers developed at the National Centre for Energy Research and Development, University of Nigeria, Nsukka were used for this study. The solar dryers used are all of natural convection type as shown in Figure 1, which include Green house solar dryer, Sun-tracking solar dryer and Latitudinal box solar dryer. Latitudinal box solar dryer is of metal body painted black. It has a perforated opening at the top and bottom of the north and the south end respectively. The glass cover is inclined at an angle of $22^{\circ}$. Green house solar dryer is made of glass at all sides except at the bottom with a perforated aluminium sheet. Sun-tracking solar dryer has a manual sun tracking system. It is covered with glass on both the top and on one side with the rest covered with metal. It is perforated at the bottom and along its door as shown in Figures 1a-c.

\section{Plant materials}

Tomato fruits (plum variety) bought from Nsukka main market was used for this study. They were washed and sliced uniformly. Random samples from the chips were analyzed for vitamins A, C, and E using the official methods of analysis of the Association of Official Analytical Chemists, AOAC [11]. The initial moisture content was also analysed using MB 35 Halogen moisture meter. They were then divided into four parts, each for the three dryers and one part for open-air sun drying as control for the study. The ambient and chamber temperatures throughout the duration of the process were measured using I-BK Precision thermocouple, while relative humidity of the

${ }^{*}$ Corresponding author: J. I. Eze, National centre for energy research and development, University of Nigeria, Nsukka, Enugu state, Nigeria, Tel: +2348063285864 E-mail: ikejon85@yahoo.com

Received May 16, 2012; Accepted August 18, 2012; Published August 252012

Citation: Eze JI (2012) Studies on the Effect of Different Solar Dryers on the Vitamin Content of Tomato (Solanum lycopersicon). J Food Process Technol 3:179. doi:10.4172/2157-7110.1000179

Copyright: (c) 2012 Eze Jl. This is an open-access article distributed under the terms of the Creative Commons Attribution License, which permits unrestricted use, distribution, and reproduction in any medium, provided the original author and source are credited. 
systems was measured with Vaisala Humidity Indicator. The weight loss during drying which was assumed to be only moisture loss was monitored periodically by weighing the samples until the weight was constant. It was used to determine moisture content periodically. The vitamin analyses of the dried samples were determined and the results compared with fresh (undried) ones.

\section{Statistical design and method}

The vitamin analysis was done using the Completely Randomized Design (CRD) statistical method. The analysis of variance table for CRD is as shown in Table 1 [12].

The decision rule for CRD is if F-calculated is greater than or equal to F-tabulated at a given probability level then the $\mathrm{F}$ test is significant. A significant $\mathrm{F}$ test means that at least one of the drying systems (treatments) is significantly different. Then, the multiple comparison Test using equation 1 was done to find out which treatment differs from others (Obi, 2002).

$$
F-L S D_{.05}=\left(t_{. \frac{05}{2}}, \text { Error d.f. }\right) \sqrt{\frac{2 \star S^{2}}{r}}
$$

If the difference between two means is greater than the F-LSD. $\mathrm{H}_{\mathrm{o}}$ is rejected with the conclusion that the two mean are statistically different.

\section{Results and Discussion}

The ambient and chamber temperatures throughout the duration

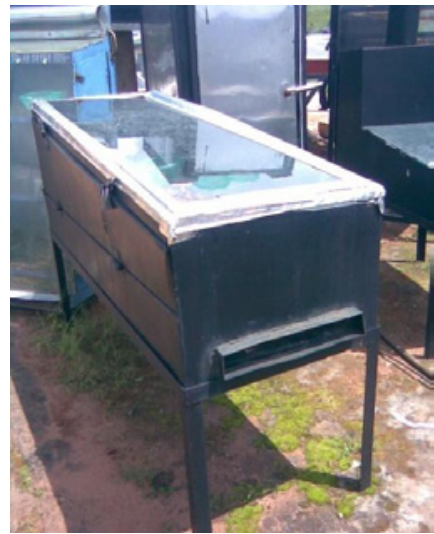

Figure 1a: Latitudinal box solar dryer.

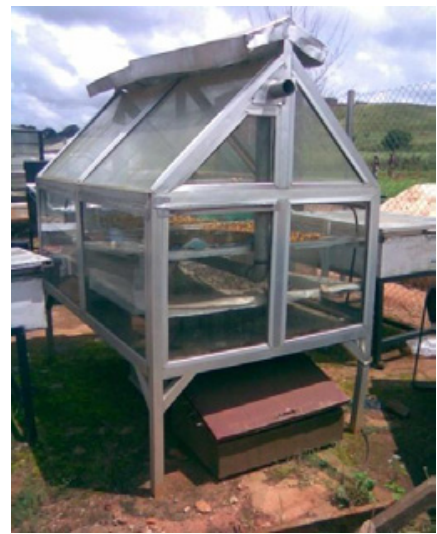

Figure 1b: Green house solar dryer.

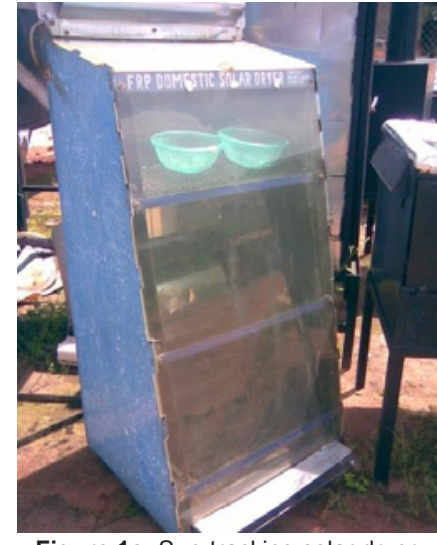

Figure 1c: Sun-tracking solar dryer.

of the process excluding night periods ranged between $27.1-35.5^{\circ} \mathrm{C}$ (ambient), $29.8-54.8^{\circ} \mathrm{C}$ (Latitudinal box dryer), $28.6-50.8^{\circ} \mathrm{C}$ (Greenhouse dryer), and $27.5-62.0^{\circ} \mathrm{C}$ (Sun-tracking dryer) with ambient temperature having the least values for all readings as shown in Figure 2a. The maximum relative humidity recorded were $85.0 \%$ (ambient), 74.5\% (Latitudinal box dryer), 78.0\% (Greenhouse dryer), and $73.0 \%$ (Sun-tracking dryer) with ambient relative humidity having the highest values for all readings as shown in Figure $2 \mathrm{~b}$.

At an interval of two hours, each sample was weighed and moisture content calculated from the weight loss. These figures were monitored until the samples were physically dried. The results showed that after three days of drying, the moisture content of tomato dropped from $2531.58 \%$ db to $50.58 \%$ db (open-air), $8.817 \%$ db (“A”), $35.17 \%$ db ("B"), $19.3 \% \mathrm{db}$ ("C"). The monthly average daily radiation for the month of April during which the study was done has been estimated to be $17.730 \mathrm{MJm}^{-2} \mathrm{day}^{-1}$ for Nsukka [13].

The result of the analysis of CRD showed varying significant difference for all vitamins (Table 2). The dried samples for all drying systems showed significant different vitamin concentrations from the fresh samples. This simply means that there was an acceptable change in vitamins concentrations as a result of the drying. The superscript in Table 2 shows the level of significance in the concentrations in descending order; a representing the highest yield while e represents the lowest yield. The three dryers showed no significant difference in vitamin A but different from open-air system.

While there are losses of vitamin $\mathrm{C}$ concentration in all the drying methods used, Vitamins A and $\mathrm{E}$ concentrations in the solar dryers increased significantly. Vitamin $\mathrm{C}$ is a water soluble vitamin and is rapidly destroyed by heat. Vitamin A and $\mathrm{E}$ were not affected by heat but susceptible to light and air as can be observed in solar dried samples. Thus, it can be noted from (Table 2) that sun-tracking dryer recorded the lowest value of vitamins $\mathrm{A}$ and $\mathrm{E}$ among the solar dryers used due constant tracking of light. The concentrations of vitamin A and $\mathrm{E}$ in the open-air system were generally low due to exposure to both light and wind when compared to solar dryers. The result of the sensory evaluation of the samples indicates that open-air dried samples had less acceptability when compared to solar dried samples. This perhaps could be attributed to exposure of the samples to UVs from the sun which adversely affected its colour and darkened the samples after prolonged exposure to direct sunlight [6].

\section{Conclusion}

Samples of tomato fruit were dried in the open-air and with 
Citation: Eze JI (2012) Studies on the Effect of Different Solar Dryers on the Vitamin Content of Tomato (Solanum lycopersicon). J Food Process Technol 3:179. doi:10.4172/2157-7110.1000179

Page 3 of 3

\begin{tabular}{|c|c|c|c|c|c|}
\hline Sources of Variation & $\begin{array}{l}\text { Degrees of Freedom } \\
\text { (DF) }\end{array}$ & Sum of Squares (SS) & Mean Squares (MS) & F-Cal & F-Tab (5\%) \\
\hline Among Treatments & $t_{a}-1$ & Among Treatments SS ( $\left.\mathrm{T}_{\mathrm{a}} \mathrm{SS}\right)$ & Among Treatments MS $=\mathrm{TMS}=\left(\mathrm{T}_{\mathrm{a}} \mathrm{SS}\right) /\left(\mathrm{t}_{\mathrm{a}}-1\right)$ & TMS/EMS & $\begin{array}{l}\text { From statistical } \\
\text { table }\end{array}$ \\
\hline $\begin{array}{l}\text { Within Treatments } \\
\text { (Experimental error) }\end{array}$ & $t_{a}(r-1)$ & $\begin{array}{l}\text { Within Treatments SS } \\
(E S S)=T_{S S}-T_{a} S S\end{array}$ & Within Treatments MS $(E M S)=E S S /\left(t_{a}(r-1)\right)$ & - & - \\
\hline Total & $t_{a} r-1$ & Total SS (TSS) & - & - & - \\
\hline
\end{tabular}

(Obi, 2002)

Table 1: The ANOVA Format for a Completely Randomized Design (CRD).

\begin{tabular}{|c|c|c|c|c|c|}
\hline Vitamins & Fresh samples/dryers & A & B & C & $\mathrm{D}$ \\
\hline$A(I U) \times 10^{2}$ & $8.71 \pm 0.01^{c}$ & $96.13 \pm 0.57^{a}$ & $96.13 \pm 0.47^{a}$ & $95.11 \pm 0.11^{a}$ & $58.71 \pm 0.08^{b}$ \\
\hline$C(\mu g)$ & $500 \pm 0.03^{e}$ & $82.45 \pm 0.07^{d}$ & $272.25 \pm 0.07^{b}$ & $189.85 \pm 0.07^{c}$ & $409.66 \pm 0.13^{a}$ \\
\hline$E(\mathrm{mg})$ & $0.94 \pm 0.01^{e}$ & $41.95 \pm 0.04^{a}$ & $23.94 \pm 0.09^{b}$ & $22.53 \pm 0.11^{b}$ & $6.29 \pm 0.06^{d}$ \\
\hline
\end{tabular}

Table 2: The Vitamin Analysis of Pawpaw.

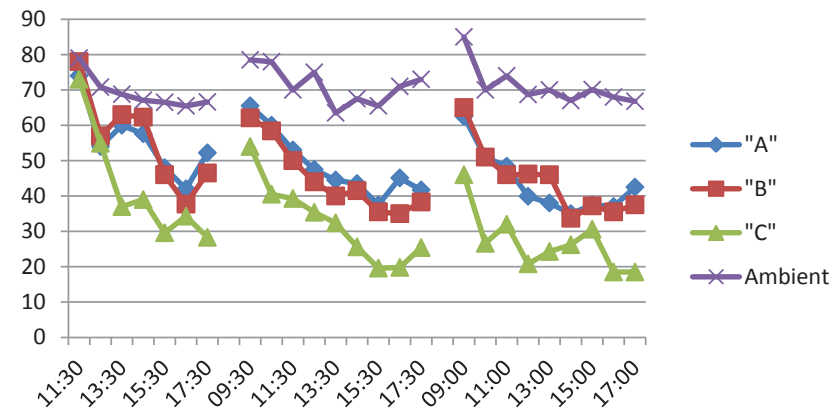

Figure 2a: Relative Humidity of the dryers against Time.

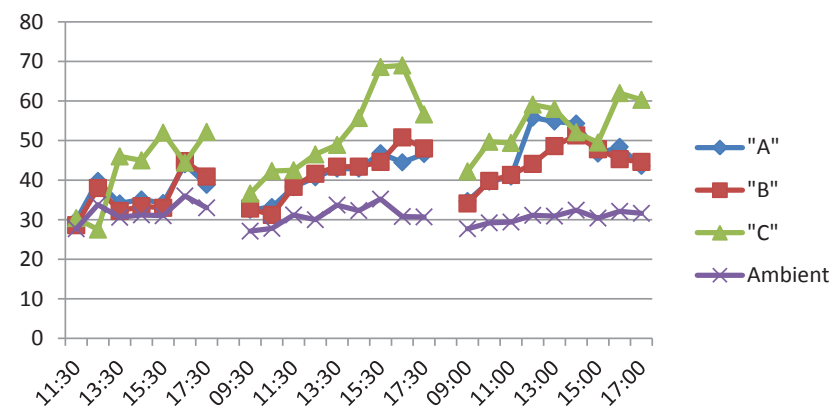

Figure $\mathbf{2 b}$ : Temperature Readings of the deryers against Time.

solar dryers. Vitamin A, C and E were analysed to determine their concentrations before and after drying. In all cases, there were significant changes in the concentration of vitamins after drying. For vitamin $\mathrm{A}$, there was no significant difference among the solar dryers used while they varied significantly from open-air drying system. Among the drying systems used, open-air system gave the highest yield in vitamin $\mathrm{C}$ concentration while latitudinal box dryer gave the highest yield of vitamin $\mathrm{C}$ and $\mathrm{E}$ concentrations'. Hence, the use of solar dryers for drying tomato increase the concentration of fat soluble vitamins while open-air system enhances water soluble vitamins better than solar dryers.

\section{References}

1. Grubeen H (2003) Food Composition Data, Food and Agriculture Organisation of the United Nations. Academic Press, New York.

2. Orwa C, Mutua A, Kindt R, Jamnadass R, Simons A (2009) Agroforestree
Database: atree reference and selection guide version 4.0. Accessed online on18th September, 2010.

3. Ojike O, Nwoke OO, Okonkwo WI (2010) Comparative Evaluation of Passive Solar Dryers using the Drying Rate Constants of Yellow Pepper and Okro as a Case Study. Nigerian Journal of Solar Energy 21: 156-164

4. Ekechukwu OV, Norton B (1999) Review of Solar Energy Systems: An Overview ofSolar Drying Technology. Energy Conversion and Management 40: 615-655.

5. Muthuverrappan VR, Ambalavanan G, Kunchithapatham M, kamaraj G, Ananthanatesan T (1985) Low Cost Plastic Suction-type-greenhouse Grain Dryer. Proceedings ISES Conference, INTERSOL 85: 1077-1781.

6. Whitefield D (2000) Solar Dryer Systems and the Internet: Important Resources to Improve Food.

7. Eze Jl, Chibuzor EE (2008) Evaluation of Drying Efficiency of Solar Cabinet Dryer using Okro and Tomato. Nigerian Journal of Solar Energy 19: 25-33.

8. Okonkwo WI, Nwoke OO (2008) Family Size Green House Solar Energy Crop Dryer.Nigerian Journal of Solar Energy 19: 6-10

9. Oparaku NK (2008) Development and Performance Evaluation of MediumScale Solar Fish Dryer. Nigerian Journal of Solar Energy 19: 34-39.

10. Okonkwo WI, Okoye EC (2005) Performance Evaluation of a Pebble Bed Solar CropDryer. Nigerian Journal of Technology 24: 67-73.

11. Eze Jl, Ekechukwu OV (1999) Improved Studies on Tomato Preservation using a Solar Dryer. Renewable Energy 7: 67-72.

12. Obi IU (2002) Statistical Methods of Detecting Differences Between Treatment Means and Research Methodology Issues in Laboratory and Field Experiments. Snaap Press (Nig) LTD, Enugu.

13. Greenfield H, Southgate DAT (2003) Food composition data: Production Management and Use, 2nd Edition FAO, Rome.

14. Agbo SN, Ezema FI (2008) Estimation of the monthly average daily global solar radiation in Nsukka, Nigeria. Nigerian Journal of Solar Energy 19: 40-47. 